\title{
PENGARUH KOMPENSASI, IKLIM KERJA DAN BUDAYA ORGANISASI TERHADAP KINERJA KARYAWAN CV. BAHARI TEKNIK GEDANGAN SIDOARJO
}

\author{
*Tyas Ayu Alfitri1, Musriha, RM Bramastyo \\ Prodi Manajemen Fakultas Ekonomi dan Bisnis Universitas Bhayangkara, Indonesia
}

DOI: $10.46821 /$ benchmark.v1i1.20

\begin{abstract}
Abstrak
Penelitian ini bertujuan untuk menguji dan menganalisis pengaruh kompensasi, iklim kerja dan budaya organisasi terhadap kinerja karyawan CV. Bahari Teknik Gedangan Sidoarjo. Penelitian ini menggunakan teknik pengumpulan data yaitu observasi, wawancara dan kuisioner. Populasi penelitian adalah seluruh karyawan CV. Bahari Teknik Gedangan Sidoarjo, dengan sampel diambil dengan menggunakan sampling jenuh. Teknik analisis data pada penelitian ini menggunkan bantuan SPSS, dengan pengujian data yang digunakan dalam penelitian ini meliputi uji validitas, uji asumsi klasik, uji reabilitas dan analisis regresi linier berganda.Hasil penelitian menunjukkan bahwa secara simultan dan parsial kompensasi, iklim kerja dan budaya organisasi berpengaruh signifikan terhadap kinerja karyawan CV. Bahari Teknik Gedangan Sidoarjo. Sedangkan dari hasil penguiian regresi maka dapat disimpulkan bahwa variabel yang paling dominan berpengaruh terhadap kinerja karyawan CV. Bahari Teknik Gedangan Sidoarjo adalah iklim kerja, hal ini dikarenakan dengan adanya iklim kerja yang kondusif dan fasilitas yang cukup yang diberikan oleh perusahaan maka akan mempengaruhi peningkatan kinerja karyawan pada CV. Bahari Teknik Gedangan Sidoarjo.
\end{abstract}

Kata kunci : Kompensasi, Iklim Kerja, Budaya Organisasi

\section{Abstract}

This study aims to examine and analyze the effect of compensation, work climate and organizational culture on employee performance CV. BAHARI TEKNIK GEDANGAN SIDOARJO. This study uses data collection techniques, namely observation, interviews and questionnaires. The study population was all employees CV. BAHARI TEKNIK GEDANGAN SIDOARJO with samples taken using saturated sampling. Data analysis techniques in this study using SPSS assistance, by testing the data used in this study include validity test, classic assumption test, reliability test and multiple linear regression analysis. The results showed that simultaneously and partially compensation, work climate and organizational culture had a significant effect on employee performance CV. BAHARI TEKNIK GEDANGAN SIDOARJO. Whereas from the results of regression testing it can be concluded that the most dominant variable affecting employee performance CV. BAHARI TEKNIK GEDANGAN SIDOARJO is the work climate, this is due to the existence of a conducive work climate and adequate facilities provided by the company will affect the improvement in employee performance CV. BAHARI TEKNIK GEDANGAN SIDOARJO.

Keywords: Compensation, Work Climate, Organizational Culture

*Corresponding Author:

Hal: 19-24

Email: tyasaa70@gmail.com 
Persaingan antar perusahaan di era globalisasi semakin tajam, sehingga sumber daya manusia (SDM) dituntut untuk terus-menerus mampu mengembangkan diri secara proaktif. SDM harus menjadi manusia-manusia pembelajar, yaitu pribadi yang mau belajar dan bekerja keras dengan penuh semangat, sehingga potensi dapat berkembang maksimal. Oleh karena itu, SDM yang diperlukan pada saat ini adalah SDM yang sanggup menguasai teknologi dengan cepat, adaptif dan reponsif terhadap perubahanperubahan teknologi. Permasalahan dalam suatu perusahaan terkait dengan sumber daya manusia adalah bagaimana menciptakan sumber daya manusia yang berkualitas. Sehingga dengan keadaan seperti itu perusahaan dituntut untuk lebih selektif dalam memperoleh tenaga kerja yang benar-benar sesuai dengan kebutuhan perusahaan, sehingga apa yang menjadi tujuan perusahaan dapat tercapai salah satunya dengan cara meningkatkan kinerja karyawan. SDM merupakan salah satu faktor yang sangat penting bahkan tidak dapat dilepaskan dari sebuah organisasi, baik institusi maupun perusahaan.

Menurut Rivai dalam Septawan (2014:5) kompensasi merupakan sesuatu yang diterima karyawan sebagai pengganti kontribusi jasa mereka pada perusahaan. Stringer (2013:130) menggambarkan iklim kerja dalam organisasi dengan konsep segala sesuatu yang terdapat pada lingkungan kerja, yang dirasakan secara langsung maupun tidak oleh orang-orang yang berbeda-beda dalam lingkungan tersebut. Menurut Robbins dan Coulter (2013:51) menyatakan bahwa budaya organisasi adalah nilai, prinsip dan sikap yang mempengaruhi cara berindak anggota organisasi. Harsuko (dalam Priansa, 2016:39) "menyatakan bahwa kinerja adalah sejauh mana seseorang telah melaksanakan strategi perusahaan, baik dalam mencapai sasaran khusus yang berkaitan dengan peran perseorangan atau dengan memperlihat kompetensi yang dinyatakan relevan bagi perusahaan".

\section{METODE PENELITIAN}

Menurut Sugiyono (2016:93), skala likert digunakan untuk mengukur sikap, pendapat dan persepsi seseorang atau sekelompok orang tentang fenomena sosial. Dengan skala likert, maka variabel yang akan diukur dijabarkan menjadi indikator variabel. Kemudian indikator tersebut dijadikan sebagai tolak ukur untuk menyusun item-item instrument yang dapat berupa pernyataan dengan pemberian skor antara lain:
a. Sangat Setuju (SS) $=5$
b. $\quad$ Setuju (S) $=4$
c. Kurang Setuju (KS) = 3
d. Tidak Setuju (TS) = 2
e. $\quad$ Sangat Tidak Setuju (STS) $=1$

Variabel bebas $(\mathrm{X})$, merupakan variabel yang diduga mempengaruhi variabel terikat. Menurut Sugiyono (2016:117), populasi adalah wilayah generalisasi yang terdiri atas obyek/subyek yang mempunyai kualitas dan karakteristik tertentu yang ditetapkan oleh peneliti untuk dipelajari dan kemudian ditarik kesimpulannya. Populasi dalam ini dipergunakan adalah seluruh karyawan CV. Bahari Teknik Gedangan Sidoarjo yang berjumlah 54 orang.

Sampel adalah bagian dari populasi (sebagian atau wakil dari populasi yang diteliti). Sampel penelitian adalah sebagian dari populasi yang di ambil sebagai sumber 
data dan dapat mewakili seluruh populasi. Adapun penelitian jumlah sampel yang digunakan oleh penulis dalam penelitian jumlah sampel yang digunakan oleh penulis dalam penelitian ini adalah dengan metode sensus berdasarkan pada ketentuan yang dikemukakan Sugiyono (2016:61), yang mengatakan bahwa "sampling jenuh adalah teknik penentuan sampel bila semua anggota populasi digunakan sebagai sampel. Istilah lain dari sampling jenuh adalah sensus". Adapun yang menjadi sampel penelitian ini adalah seluruh karyawan CV. Bahari Teknik Gedangan Sidoarjo yang berjumlah 54 sampel.

Jenis data yang digunakan yaitu Data Primer, Data Sekunder. Teknik pengumpulan data dapat dilakukan dengan interview (wawancara), kuisioner (angket) dan observasi (pengamatan). Teknik analisis data yang digunakan dalam penelitian ini adalah analisis kuantitatif. Analisis kuantitatif adalah cara menganalisis data yang berbentuk angka yang membandingkan antara yang satu dengan yang lain.

\section{HASIL ANALISIS DAN PEMBAHASAN}

\section{Uji Validitas $=(\mathbf{d f})=\mathbf{n}-2$}

Dari tabel 1, menujukkan bahwa dari indikator-indikator variabel yang digunakan dalam penelitian ini semuanya memiliki nilai korelasi diatas 0,273 . Hal ini berarti bahwa semua indikator yang digunakan untuk mengukur semua variabel dalam penelitian ini dinyatakan mempunyai validitas yang tinggi.

\section{Tabel 1}

Pengujian Validitas Instrumen

\begin{tabular}{|c|c|c|c|}
\hline \multirow[t]{2}{*}{ Item Pernyataan } & Hasil Korelasi & Nilai Kritis & \multirow[t]{2}{*}{ Keterangan } \\
\hline & $r_{\text {hitung }}$ & $r_{\text {table }}$ & \\
\hline \multicolumn{4}{|c|}{ Kompensasi (X1) } \\
\hline X1.1 & 0,805 & 0,273 & VALID \\
\hline $\mathrm{X} 1.2$ & 0,681 & 0,273 & VALID \\
\hline $\mathrm{X} 1.3$ & 0,728 & 0,273 & VALID \\
\hline $\mathrm{X} 1.4$ & 0,790 & 0,273 & VALID \\
\hline $\mathrm{X} 1.5$ & 0,759 & 0,273 & VALID \\
\hline \multicolumn{4}{|c|}{ Iklim Kerja (X2) } \\
\hline $\mathrm{X} 2.1$ & 0,701 & 0,273 & VALID \\
\hline $\mathrm{X} 2.2$ & 0,615 & 0,273 & VALID \\
\hline $\mathrm{X} 2.3$ & 0,555 & 0,273 & VALID \\
\hline $\mathrm{X} 2.4$ & 0,638 & 0,273 & VALID \\
\hline \multicolumn{4}{|c|}{ Budaya Organisasi (X3) } \\
\hline X3.1 & 0,536 & 0,273 & VALID \\
\hline $\mathrm{X} 3.2$ & 0,504 & 0,273 & VALID \\
\hline X3.3 & 0,548 & 0,273 & VALID \\
\hline \multicolumn{4}{|c|}{ Kinerja Karyawan $(\mathrm{Y})$} \\
\hline Y1 & 0,673 & 0,273 & VALID \\
\hline Y2 & 0,570 & 0,273 & VALID \\
\hline Y3 & 0,665 & 0,273 & VALID \\
\hline Y4 & 0,679 & 0,273 & VALID \\
\hline
\end{tabular}

Sumber: Peneliti (2019) 


\section{Uji Reliabilitas}

Berdasarkan diatas terlihat bahwa variabel bebas yang terdiri dari Kompensasi(X1), Iklim Kerja (X2) dan Budaya Organisasi (X3), serta variabel terikat Kinerja Karyawan (Y) masing-masing memiliki nilai Alpha Cronbach yang lebih besar dari 0,6 kondisi ini memberikan arti bahwa seluruh variabel tersebut adalah reliabel dan dapat digunakan pada analisis selanjutnya (Tabel 2).

\section{Uji Regresi Linier Berganda}

Dari tabel 3, diperoleh persamaan regresi linier berganda sebagai berikut:

$$
\begin{aligned}
& Y=a+b_{1} X_{1}+b_{2} X_{2}+b_{3} X_{3} \\
& Y=8,405+0,215 X_{1}+\mathbf{0 , 5 3 2}_{2}+\mathbf{0 , 2 7 6 X _ { 3 }}
\end{aligned}
$$

Tabel 2

Hasil Uji Reabilitas

\begin{tabular}{ccc}
\hline Variabel / Indikator & Nilai Alpha & Keterangan \\
\hline Kompensasi (X1) & 0,899 & Reliabel \\
Iklim Kerja (X2) & 0,809 & Reliabel \\
Budaya Organisasi (X3) & 0,710 & Reliabel \\
Kinerja Karyawan (Y) & 0,823 & Reliabel \\
\hline
\end{tabular}

Sumber: Peneliti (2019)

\section{Tabel 3}

Hasil Analisis Regresi Linier Berganda .Coefficients ${ }^{\mathrm{a}}$

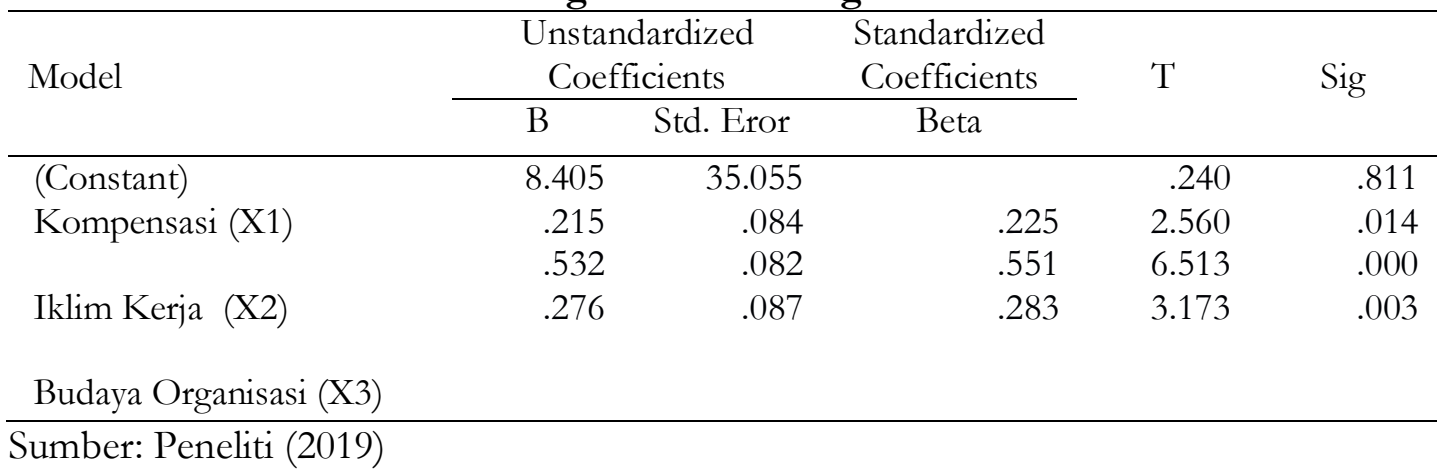

Tabel 4

Uji Simultan (Uji F) ANOVA ${ }^{a}$

\begin{tabular}{rlrrrrr}
\hline \multicolumn{1}{l}{ Model } & Sum of Squares & Df & Mean Square & F & Significance \\
\hline \multirow{3}{*}{1} & Regression & 132963.690 & 3 & 44321.230 & 42.398 &, $000^{\mathrm{b}}$ \\
Residual & 52267.792 & 50 & 1045.356 & & \\
Total & 185231.481 & 53 & & & \\
\hline
\end{tabular}

Sumber: Peneliti (2019) 
Tabel 5

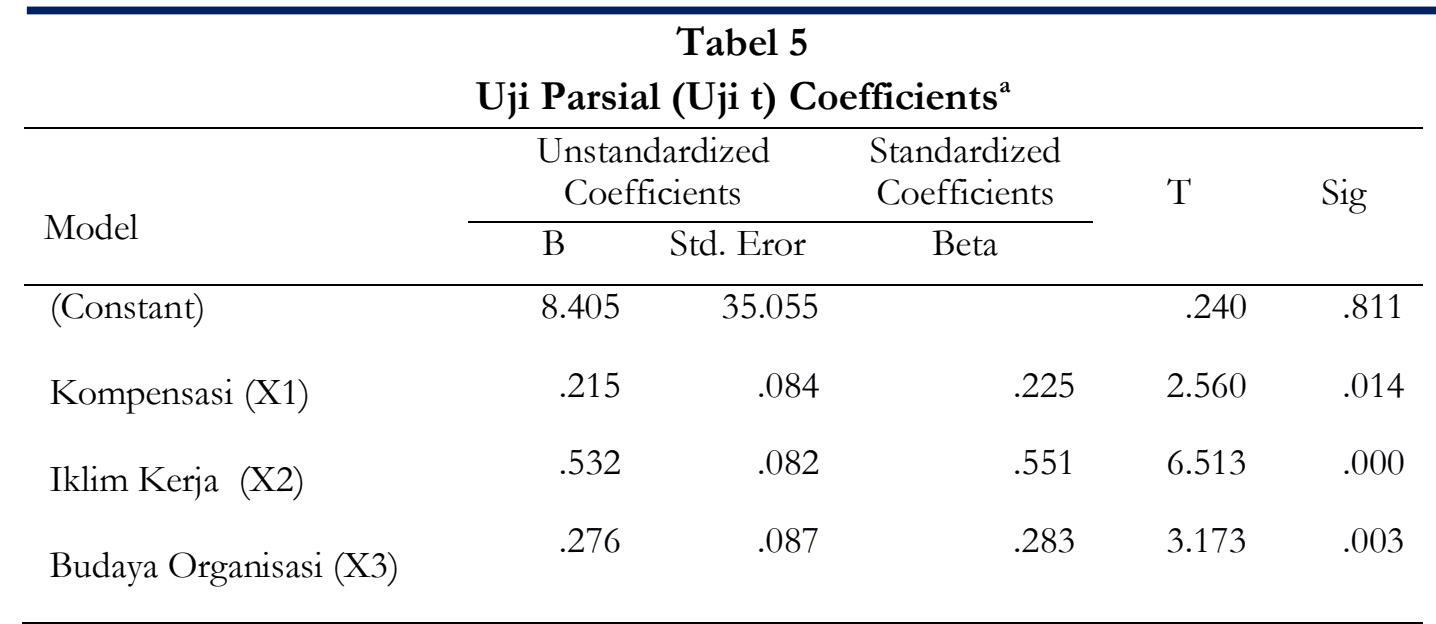

Sumber: Peneliti (2019)

\section{SIMPULAN}

Bedasarkan hasil penelitian dan pembahasan yang digunakan sesuai hipotesis yang dilakukan, maka dapat diambil kesimpulan sebagai berikut: 1) Kompensasi $\left(\mathrm{X}_{1}\right)$, Iklim Kerja $\left(\mathrm{X}_{2}\right)$, Budaya Organisasi $\left(\mathrm{X}_{3}\right)$ berpengaruh secara simultan terhadap Kinerja Karyawan (Y) pada CV. Bahari Teknik Gedangan Sidoarjo. Hasil pengujian model secara bersama-sama (simultan) di atas diperoleh nilai $F_{\text {hitung }}$ sebesar 42.398. Nilai ini lebih besar dari pada $F_{\text {tabel }}$ sebesar 2,79. Demikian juga dengan nilai signifikan yang dihasilkan sebesar 0,000 yang lebih kecil dari nilai signifikan yang digunakan yaitu $\alpha=5 \%$ atau 0,05 , Sehingga dapat disimpukan bahwa Ho ditolak dan Ha diterima. Artinya bahwa variabel Kompensasi $\left(\mathrm{X}_{1}\right)$, Iklim Kerja $\left(\mathrm{X}_{2}\right)$, Budaya Organisasi $\left(\mathrm{X}_{3}\right)$ secara simultan (bersamasama) memiliki pengaruh yang signifikan terhadap Kinerja Karyawan (Y) pada karyawan CV. Bahari Teknik Gedangan Sidoarjo. 2) Variabel Kompensasi $\left(\mathrm{X}_{1}\right)$, Iklim Kerja $\left(\mathrm{X}_{2}\right)$, Budaya Organisasi $\left(\mathrm{X}_{3}\right)$ berpengaruh secara parsial terhadap Kinerja Karyawan $(\mathrm{Y})$ pada CV. Bahari Teknik Gedangan Sidoarjo. Bedasarkan uji parsial untuk variabel bebas yaitu Kompensasi $\left(\mathrm{X}_{1}\right)$ nilai $\mathrm{t}_{\text {hitung }}$ sebesar 2,560 $>\mathrm{t}_{\text {tabel }}$ 1,67591 dengan nilai signifikan 0,014 lebih kecil daripada 0,05 atau 5\% (terbukti) mempunyai pengaruh secara parsial terhadap Kinerja Karyawan (Y). Hal ini sesuai dengan Made (2015) mengemukakan "bahwa perlu diperhatikan bagi perusahaan memberikan imbalan tidak serta hanya memberikan gaji untuk upah bekerja, namun dalam pemberian kompensasi juga disesuaikan dengan layak dan adil. Bedasarkan uji parsial untuk variabel bebas yaitu Iklim Kerja $\left(\mathrm{X}_{2}\right)$ nilai $\mathrm{t}_{\text {hitung }}$ sebesar 6,513 $>\mathrm{t}_{\text {tabel }}$ 1,67591 dengan nilai signifikan 0,000 lebih kecil daripada 0,05 atau 5\% (terbukti) mempunyai pengaruh secara parsial terhadap Kinerja Karyawan (Y). Hal ini sesuai dengan Moh Mujib Khoiri (2013) "yang menyatakan iklim kerja yang baik seperti fasilitas yang memadai, pencahayaan yang cukup, ketenangan, adanya jaminan keamanan dan adanya hubungan kerja yang baik akan membuat karyawan merasa nyaman dalam bekerja sehingga dapat meningkatkan kinerja mereka. Bedasarkan uji parsial untuk variabel bebas yaitu Budaya Organisasi $\left(X_{3}\right)$ nilai $t_{\text {hitung }}$ sebesar 3,173 $>t_{\text {tabel }}$ 1,67591 dengan nilai signifikan 0,003 lebih kecil daripada 0,05 atau 5\% (terbukti) mempunyai pengaruh secara parsial terhadap Kinerja Karyawan (Y). Hal ini sesuai dengan Yeheskiel Toyang (2016) "Budaya Organisasi adalah suatu kebiasaan yang telah berlangsung lama dan dipakai serta di terapkan dalam kehidupan aktivitas kerja sebagai 
salah satu pendorong untuk meningkatkan kualitas kerja pada karyawan dan manajer perusahaan". 3) Dari pengujian simultan dan parsial variabel (X) yang terdiri dari Kompensasi, Iklim Kerja, Budaya Organisasi yang paling berpengaruh terhadap Kinerja Karyawan adalah Iklim Kerja, (terbukti) berpengaruh dominan atau secara signifikan dengan nilai standardized coefficients beta (koefisien beta yang distandarkan) terbesar yaitu sebesar 0,551 dibandingkan dengan variabel Kompensasi dan Budaya Organisasi. Perusahaan harus meningkatkan kinerja dalam hal mencapai tujuan, oleh karena itu faktor Kompensasi, Iklim Kerja dan Budaya Organisasi sangat penting bagi perusahaan untuk diperhatikan demi meningkatkan KinerjaKaryawan, seperti pemberian kompensasi secara adil dan layak, menciptakan suasana kerja lebih kondusif sehingga kerja sama antar karyawan terjalin dengan baik, penerapan budaya organisasi lebih di optimalkan. Dengan demikian jika penerapan tersebut dilakukan maka Kinerja Karyawan akan semakin meningkat. Pada Variabel Kompensasi, Perusahaan seharusnya meningkatkan maupun lebih memantau Kompensasi karyawannya. Karena kompensasi yang diberikan secara adil dan layak khususnya memberikan kompensasi lebih tinggi kepada karyawan yang mempunyai hasil kerja yang baik supaya, menjadi dorongan untuk semangat bekerja dan kinerja karyawan dapat meningkat. Pada Variabel Iklim Kerja yang memiliki pengaruh dominan, Maka dalam pengelolaannya pihak manajemen diharapkan dapat lebih membuat Iklim Kerja yang kondusif bagi karyawan, contohnya mengadakan acara makan bersama dalam beberapa minggu sekali, atau acara gathering tahunan sehingga dapat terbina hubungan komunikasi antar karyawan yang baik. Iklim kerja harus dipertahankan dan untuk lebih meningkatkan pengaruh iklim kerja terhadap kinerja karyawan, perusahaan harus lebih memperhatikan keadaan karyawan di dalam lingkungan kerja agar karyawan merasa nyaman dalam bekerja.

\section{DAFTAR PUSTAKA}

Ghozali, Imam. (2013). Aplikasi Analisis Multivariate dengan Program IBM SPSS 21 Update PLS Regresi: Badan Penerbit Universitas Diponegoro. Semarang.

Priansa, D. J.( 2016). Perencanaan \& Pengembangan SDM: Afabeta. Bandung.

Robbins, Stephen P\& Mary Coulter. 2014, Manajemen Jilid 1/ Stephen P Robbins dan Mary Coulter diterjemahkan oleh Bob Sabran, Wibi Hardani. Edisi.10, Cetakan13:Erlangga. Jakarta.

Stringer, R. (2013). Leadership and Organizational Climate. Jurnal Manajemen Magister, Vol 02, No. 01. Bandung.

Sugiyono. (2016). Metode Penelitian Kuantitatif, Kualitatif dan R\&D, Edisi Dua Puluh, CV.Alfabeta, Bandung.

Zainal Veithzal, Rivai dkk. (2014). Manajemen Sumber Daya Manusia untuk perusahaan. Edisi ke 3, Cetakan 6. Rajawali Pers. Jakarta. 